\title{
Simulation of Nonlinear Ship Flows by Density-Function Method (Second Report)
}

\author{
by Takafumi Kawamura*, Member Hideaki Miyata*, Member
}

\begin{abstract}
Summary
Following the first report ${ }^{1)}$ the validation of accuracy is made of a new computation method, WISDAM-VI, which employs the density function technique on the free surface, and two applications to practical hulls are made. The first one is a flow around a tanker model in ballast condition and it is revealed that the wave breaking motion causes momentum defect and that it interacts with the viscous flow forming complicated wake. The second one is a flow around a high speed planing craft which involves highly nonlinear free-surface flow near the stern end. These demonstrate the versatile applicability of the WISDAM-VI method.
\end{abstract}

\section{Introduction}

In the last decade, a great deal of efforts have been devoted to the development of CFD methods for the simulation of the free-surface flow around ships. One of the most important characteristics of a computational method is determined by the coordinate system employed. In most of the studies, the coordinate system which is fitted both to the hull surface and free surface is employed. Coordinate system of this type has advantage that the boundary layer around the hull surface can be resolved, and the free-surface condition can be conveniently imposed provided that the free-surface deformation is moderate. However, when the freesurface deformation is very large or wave is breaking, it is no longer advantageous or sometimes impossible to generate a free-surface fitted grid system.

In the first report ${ }^{11}$, a computational method that can cope with three-dimensional breaking wave is developed by introducing the marker-density technique to the three-dimensional curvilinear coordinate system. It enables the simultaneous simulation of the viscous flow around bodies of arbitrary shape and free surface of any configuration. Since the basic algorithm of solving the discretized Navier-Stokes equations is based on that of the WISDAM-V method ${ }^{2), 3)}$, the new method is referred as the WISDAM-VI method hereafter. The new

* Department of Naval Architecture and Ocean Engineering, University of Tokyo.

Received 10th July 1995

Read at the Autumn meeting 16, 17th Nov. 1995 method is applied to flows around a bulk carrier model and a container carrier model, which include bow wave breaking. It is revealed that this method can reproduce highly nonlinear wave with certain degree of accuracy and that the vorticity generation by the wave breaking is numerically explained.

In the present report, the further confirmation of the accuracy is made using the Wigley's hull, and another two applications are made for practical hulls. The first one is the simulation of the flow around a tanker model in ballast condition, and the energy loss due to bow wave breaking and its effect on the formation of the wake is discussed. The second one is the flow around a high speed planing craft, in which the highly nonlinear free-surface flow near the stern end of the craft is investigated.

\section{Numerical method}

Since the detailed description of the numerical method is made in the first report, only the features of the WISDAM-VI method are explained. The grid system is fitted only to the solid body surface and not to the free surface in order to cope with large deformation of the free surface. The governing equations are the Navier-Stokes equation and the continuity equation, which are discretized by the finite volume method and solved by the MAC type algorithm.

The most significant characteristics of the WISDAMVI method is the use of the marker-density method in the implementation of the kinematic free ${ }^{-}$surface condition. This technique to model the free-surface has the advantage that free-surface of arbitrary configuration can be treated in a simple way. The marker-density method is generalized or simplified version of the VOF 
method by Hirt et al. $^{4)}$ and the validity has been shown in several preceeding works ${ }^{5,6), 7)}$.

\section{Accuracy validation}

\section{1 Condition of computation}

In order to investigate into the relationship between the accuracy and the number of the grid points, simulations of the flow around the Wigley's hull are performed using three grid systems. The Wigley's hull is made of parabolic curves as

$$
x_{2}=\frac{B}{2}\left\{1-\left(\frac{2 x_{1}}{L}\right)^{2}\right\}\left\{1-\left(\frac{x_{3}}{d}\right\}^{2}\right\} .
$$

where $x_{2}$ is the offset of the hull and $L, B$ and $d$ are length, breadth and draft of the ship respectively. $L / B$ is set at 10 and $L / d$ at 16 .

The conditions of the computation are shown in Table 1. In case- $B$ the number of the grid points is increased from case- $\mathrm{A}$ in the longitudinal direction, and both the longitudinal and girthwise directions in case- $\mathrm{C}$. The finest grid system used in case- $\mathrm{C}$ is shown in Fig. 1.

\section{2 Results and discussion}

The computed results are at the final stage of computation at $T=2.0$, when the flow field has become almost steady. The value of wave height is nondimensionalized in all figures with respect to the head of the uniform flow, $U_{0}^{2} / 2 g$. The wave profiles on the hull surface obtained by the three simulations are compared with the experimental result in Fig. 2. In case- A the wave profile is rather flat, and the hump and hollow around the midship are not reproduced. Although the longitudinal number of the grid points is increased from 71 to 111 in case- $B$, this tendency is almost the same. This suggests that the longitudinal number of the grid points can not be accounted for the main reason of the discrep-
Table 1 Condition of computation for the Wigley's hull

\begin{tabular}{|c|c|c|c|}
\hline & case- $\mathrm{A}$ & case-B & case- $\mathrm{C}$ \\
\hline Grid points & $71 \times 30 \times 23$ & $111 \times 33 \times 23$ & $111 \times 33 \times 35$ \\
\hline Computational domain & $2.5 \times 0.6 \times 0.6$ & $4.0 \times 0.8 \times 0.8$ & $4.0 \times 0.8 \times 0.8$ \\
\hline Free-surface treatment & \multicolumn{3}{|c|}{ marker-density method } \\
\hline Time increment & \multicolumn{3}{|c|}{$2.0 \times 10^{-4}$} \\
\hline Time steps for acceleration & \multicolumn{3}{|c|}{2000} \\
\hline Total time steps & \multicolumn{3}{|c|}{10000} \\
\hline Time of simulation & \multicolumn{3}{|c|}{2.0} \\
\hline Reynolds number & \multicolumn{3}{|c|}{$1 \times 10^{6}$} \\
\hline Froude number & \multicolumn{3}{|c|}{0.289} \\
\hline
\end{tabular}

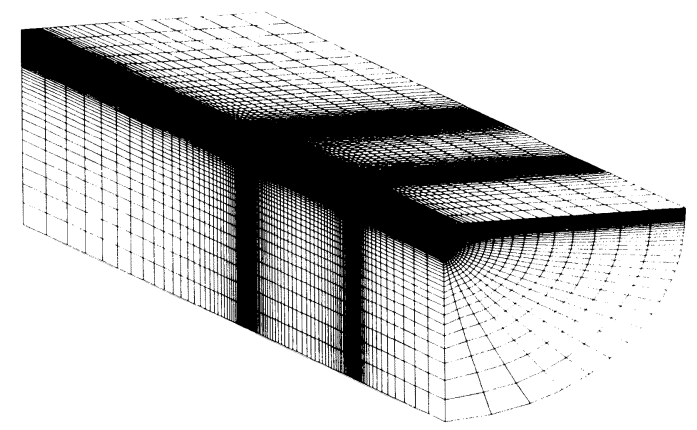

Fig. 1 Grid system for Wigley's hull (case-C)

ancy. Since the Froude number is set at 0.289 , considerably long wave is generated, so the number of the grid points per wave length may be sufficient in the near field of the ship. On the other hand, in case- $\mathrm{C}$, where the

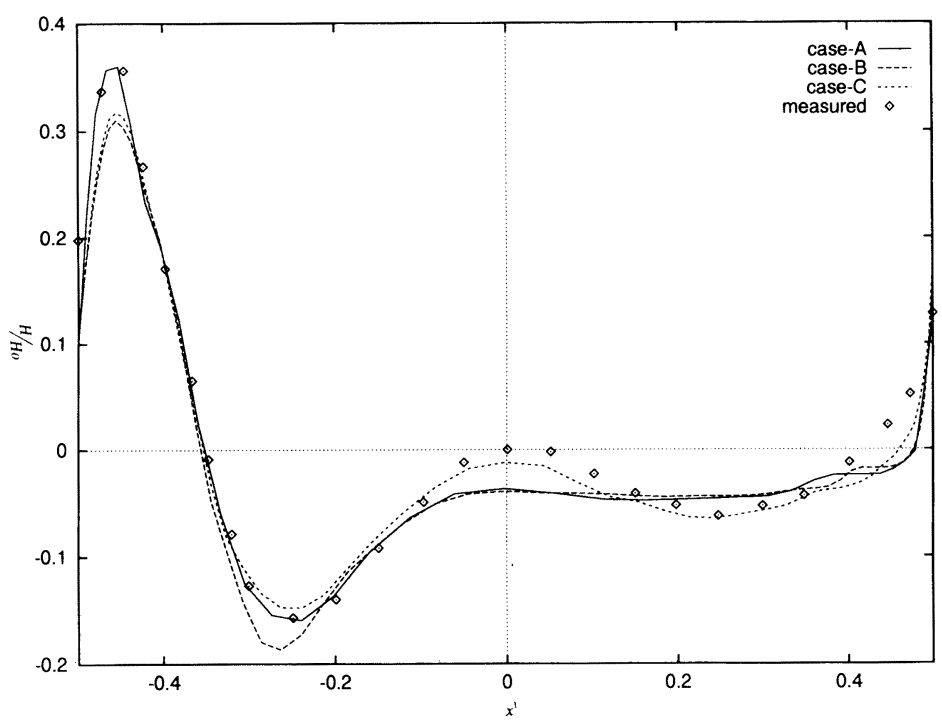

Fig. 2 Comparison of the wave profile on the hull surface of Wigley's hull 


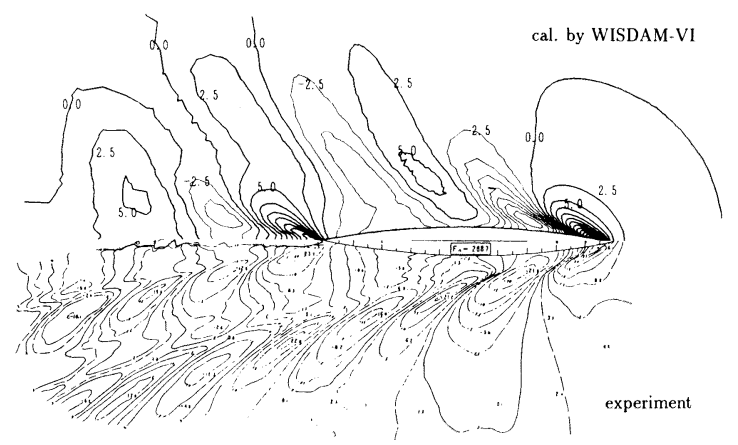

Fig. 3 Comparison of the wave contour maps

number of grid points in the vertical direction is increased from 23 to 35 , the accuracy is considerably improved and the hump and hollow is clearly seen. Because of the nature of the marker-density method, sufficient number of the grid points in the direction normal to the free-surface is necessary.

In Fig. 3 the computed and measured wave contour maps are compared. It is noted that in the far field of the ship the dispersive wave is diffused, however, in the near field of the ship both qualitative and quantitative accuracy seems to be satisfactory.

\section{Simulation of the flow around a tanker model}

\section{1 Condition of computation}

After $\mathrm{Baba}^{8)}$ first found that there is certain amount of viscous resistance associated with the expenditure of energy in generating turbulence due to the breakdown of waves at the bow of ships, many studies on this subject have been made. Miyata and Inui ${ }^{9)}$ pointed out that the discontinuity of the wave height and velocity field and the deficit of energy are the characteristics of these nonlinear bow waves. They showed the resemblance between the nonlinear bow waves and the shock waves in supersonic flow, and named them free-surface shock waves (FSSW). The FSSWs have dissipative feature and their similarity is governed by the Froude number based on ship draft.

In this section, a simulation of the flow around a tanker model SR $196 \mathrm{~A}$ is made and the features of the bow wave and its effect on the wake formation is discussed. The condition of the computation is shown in Table. 2 , and the grid system used for the simulation is shown in Fig. 4.

\section{2 Results and discussion}

Computed wave contour map is shown in Fig. 5 . Compared with the case of the Wigley's hull in Fig. 3, apparently the wave system shows dissipative feature.

In order to evaluate the dissipation of the energy in the breaking wave, the variations of the total head of the fluid on the free-surface along the quasi-streamline are shown in Fig. 6.
Table 2 Condition of computation for SR 1196 A

\begin{tabular}{|l|c|}
\hline Model & SR196A \\
\hline \hline Grid points & $111 \times 33 \times 31$ \\
Time increment & $2.0 \times 10^{-4}$ \\
Time steps for acceleration & 2000 \\
Total time steps & 10000 \\
Time of simulation & 2.0 \\
Reynolds number & $1 \times 10^{6}$ \\
Froude number & 0.150 \\
\hline
\end{tabular}

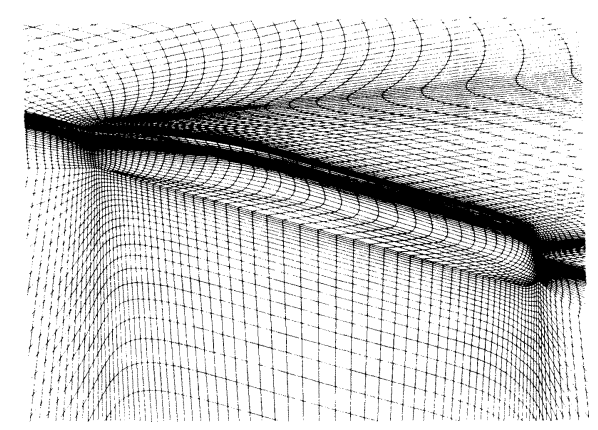

Fig. 4 Grid system for SR 196 A

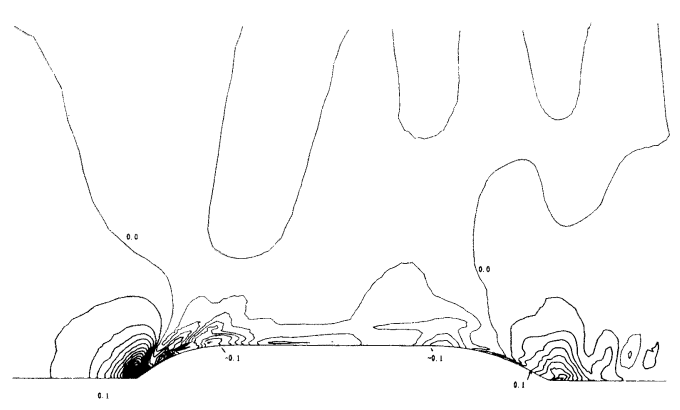

Fig. 5 Computed wave contour map of SR 196 A

The total head of the fluid is defined as follows:

$$
H=\frac{1}{2} \rho\left(u_{1}^{2}+u_{2}^{2}+u_{3}^{2}\right)+p+\rho g x_{3} .
$$

Since the static pressure $p$ on the free-surface is assumed to be the atmospheric pressure, which is set at zero as the standard pressure here, the total head on the free-surface consists of the velocity head and the potential head. Eq. (2) is made dimensionless as follows:

$$
H=\left(u_{1}^{2}+u_{2}^{2}+u_{3}^{2}\right)+\frac{x_{3}}{F n^{2}} .
$$

It is noted that discontinuity is observed both for the potential and the velocity head distribution at the wave 

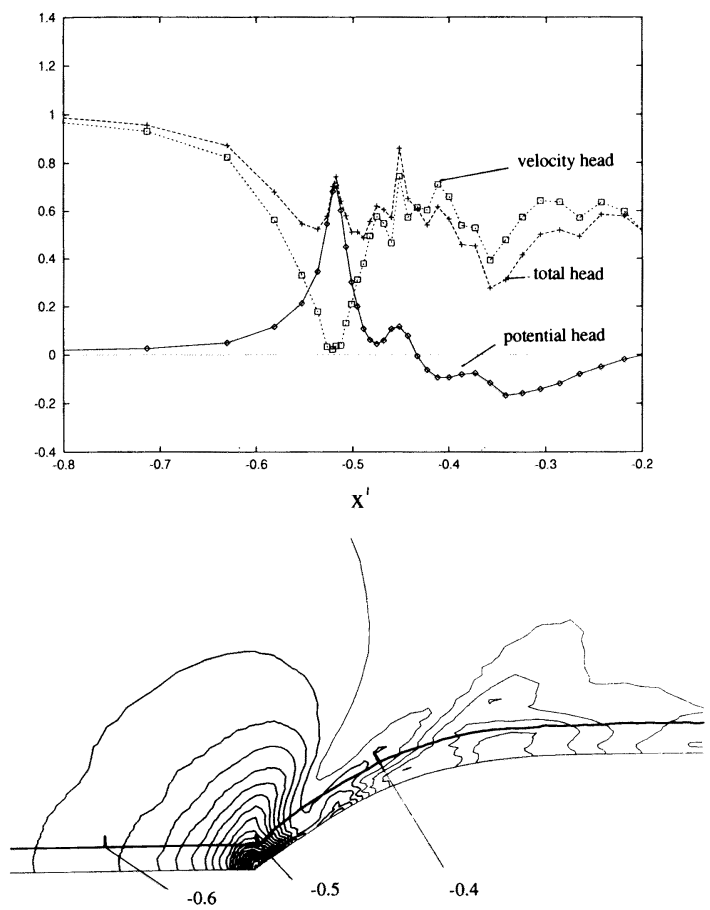

Fig. 6 Distribution of the total, velocity and potential head on the free surface for SR $196 \mathrm{~A}$

crest, and that the total head is decreased abruptly after that. The velocity head distribution indicates that the flow near the free surface is almost stagnant at the wave crest, and the resultant shear flow causes energy loss. Since the grid system is not fitted to the free surface, some error is included in the velocity on the free surface. Perhaps this is the cause of the wiggles in the velocity head distribution.

The boundary layer on the hull surface becomes thicker towards the stern, and composes wake of three -dimensional and very complicated shape. In addition, the interaction of the energy deficit due to the friction on the body surface and that of wave breaking make the shape of the wake much more complicated. As the new method WISDAM-VI employs body-fitted coordinate system, both the viscous flow in the vicinity of the body and the breaking waves can be simultaneously simulated.

Distribution of the respective components of vorticity vector and the longitudinal velocity are shown in Fig. 7. The wide distribution of $\omega_{2}$ indicates the existence of shear flow under the free--surface. The vortices due to the wave breaking, friction on the body surface and boundary layer separation are interacting each other, and compose the three-dimensional structures of the wake. However, it must be noted that the dissipative phenomena are only grossly simulated in the present simulation, since turbulence on the free surface is not well considered.

\section{Simulation of the flow around a high-speed planing craft}

\subsection{Condition of computation}

In this section, an attempt is made to apply the new computational method WISDAM-VI to the simulation of the flow around a high speed planing boat. The hydrodynamics of the flow around planing ships are quite different from that of a displacement type ships. The existence of spray at the bow is one of the most distinctive characteristics of the flow around the planing ships. The other feature is that water detaches from the bottom edge of the transom and forms a wave of large amplitude and long length. But if the water does not detach from the edge, recirculating flow behind the transom is caused and that result in high drag. Therefore, it is very important for hull form design to predict whether water detaches or not. However, since the singularity of the edge makes the prediction very difficult, in almost all the theoretical study previously made, the bottom flow is assumed to detach at the edge. Since the WISDAM-VI method employs the markerdensity method, this problem of singularity can be avoided.

A prismatic hull with a constant deadrise angle is chosen for the model of the planing craft, for extensive experimental results are available for this type of hulls. The parameters such as deadrise angle $\beta$, trim angle $\tau$, and wetted lengh-beam ratio $\lambda$, shown in Table 3 , are set so as to correspond to that of one of the experiments done by Savitsky ${ }^{10)}$. The condition of the computation is shown in Table 4, where the beam of the craft $B$ is chosen as the base of the length scale for the Reynolds number and Froude number. The grid system used for the simulation is shown in Fig. 8.

\subsection{Results and discussion}

The computation is continued until nondimensional time reaches 20.0 when the generated wave has become almost steady. The longitudinal wave profiles are shown in Fig. 9 and compared with the experimental result. Since the Froude number is very large, the generated wave is very long in the longitudinal direction, in spite of the small number of the grid points, the agreement is considerably good. On the other hand, the transverse wave profiles shown in Fig. 10 are dislocated from the experimental results. As the number of grid points in the transverse direction is only twenty, and these grid points are clustered near the side body to apply the no-slip condition there, the flow resolution in the transverse direction is insufficient.

Fig. 11 shows the evolution of the computed wave in the perspective view. The velocity of the uniform flow is constantly accelerated until nondimensional time is 5 . 0 , that is, the planing craft moves only 2.5 times as long as its beam from the rest to the top speed. Therefore, the transient transformation of the wave is very abrupt, 

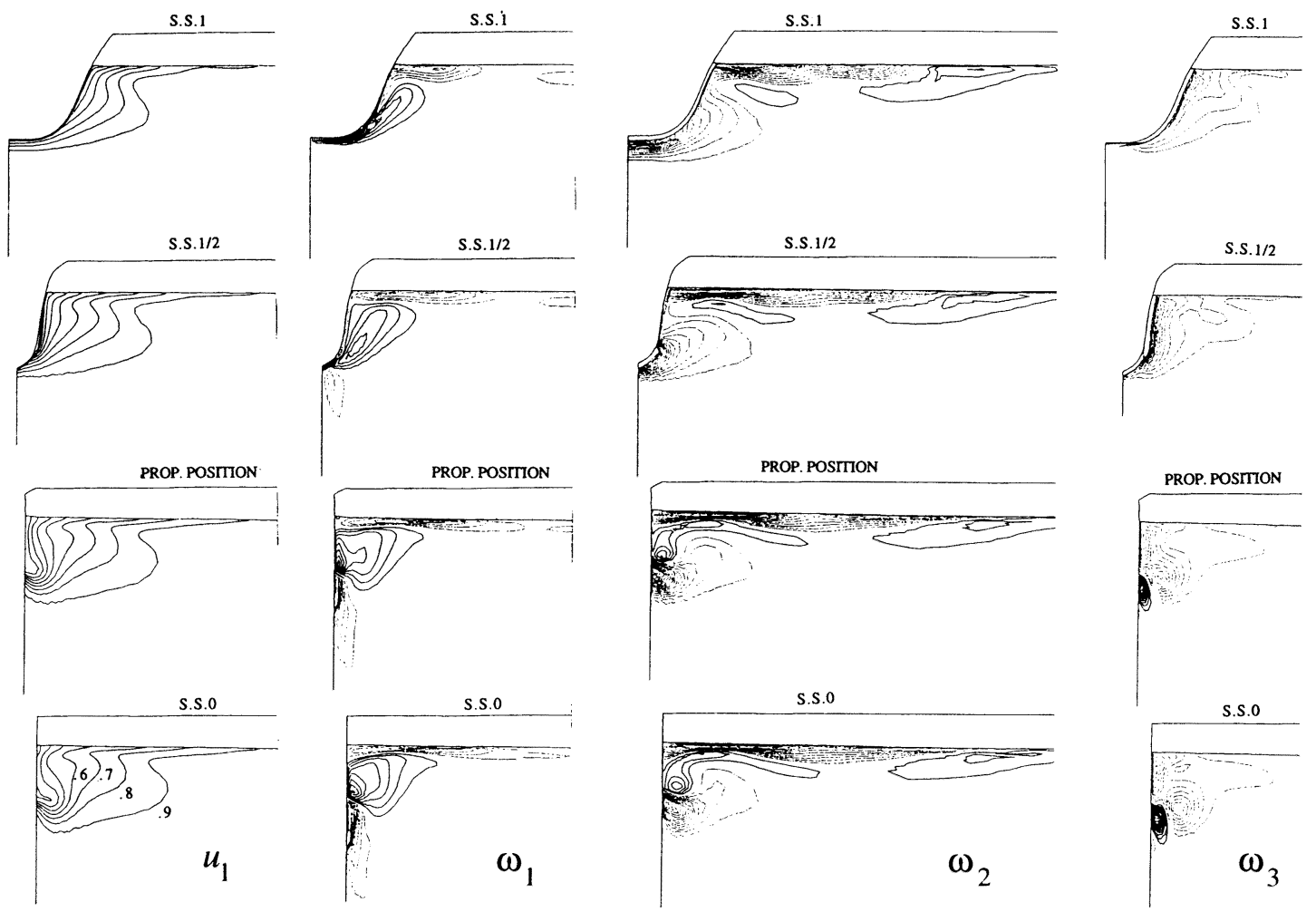

Fig. 7 Contours of streamwise velocity and vorticity components near the stern of SR 196 A

Table 3 Configuration of the planing ship model

\begin{tabular}{|l|c|}
\hline wetted length beam ratio: $\lambda$ & 2.42 \\
trim angle: $\tau$ & $8 \mathrm{deg}$ \\
deadrise angle: $\beta$ & $10 \mathrm{deg}$ \\
\hline
\end{tabular}

Table 4 Condition of computation for planing ship

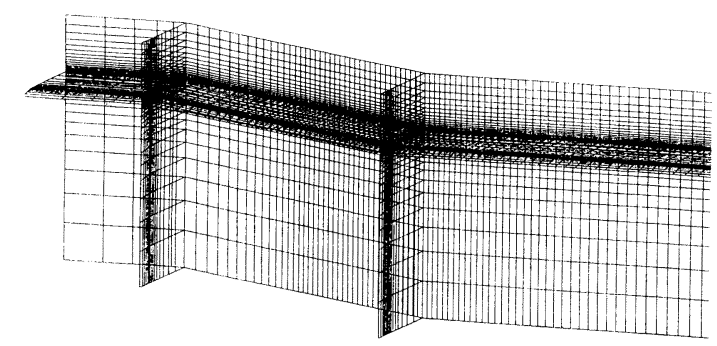

\begin{tabular}{|l|c|}
\hline Grid points & $95 \times 20 \times 40$ \\
Time increment & $2.5 \times 10^{-3}$ \\
Time steps for acceleration & 2000 \\
Total time steps & 8000 \\
Time of simulation & 20.0 \\
Reynolds number & $2 \times 10^{5}$ \\
Froude number & 3.02 \\
\hline
\end{tabular}

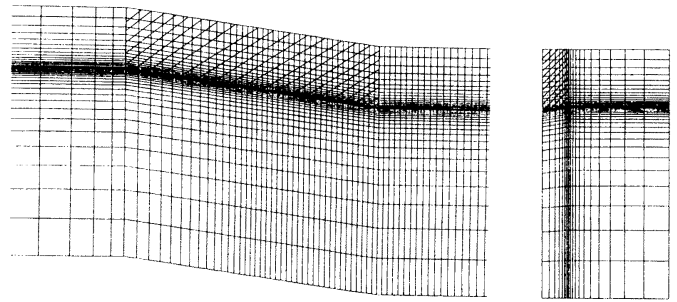

Fig. 8 Grid system for the planing craft 


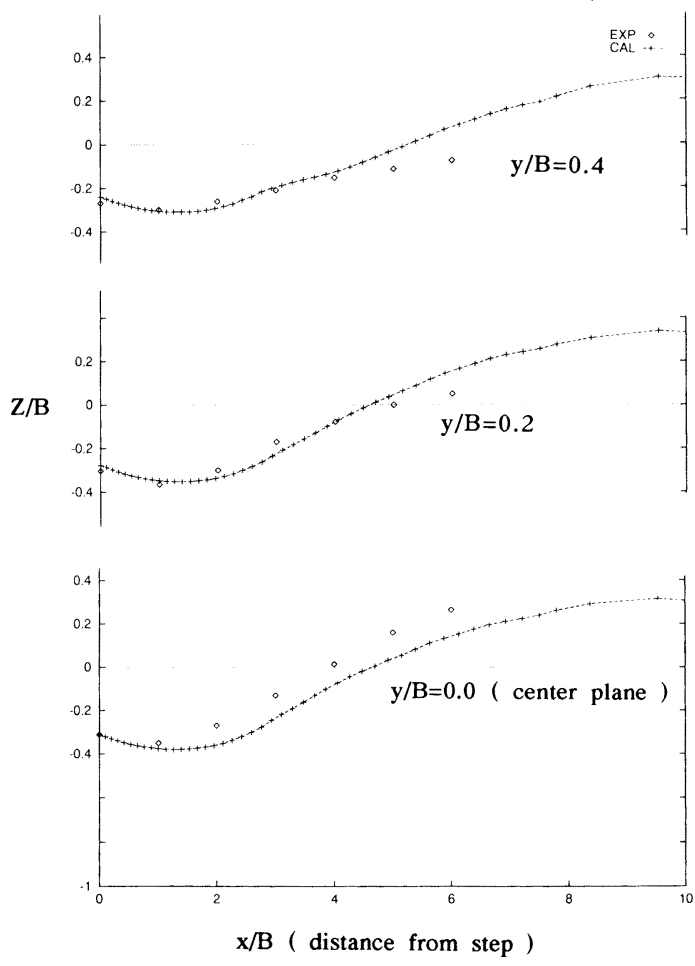

Fig. 9 Longitudinal wave profile of the planing craft

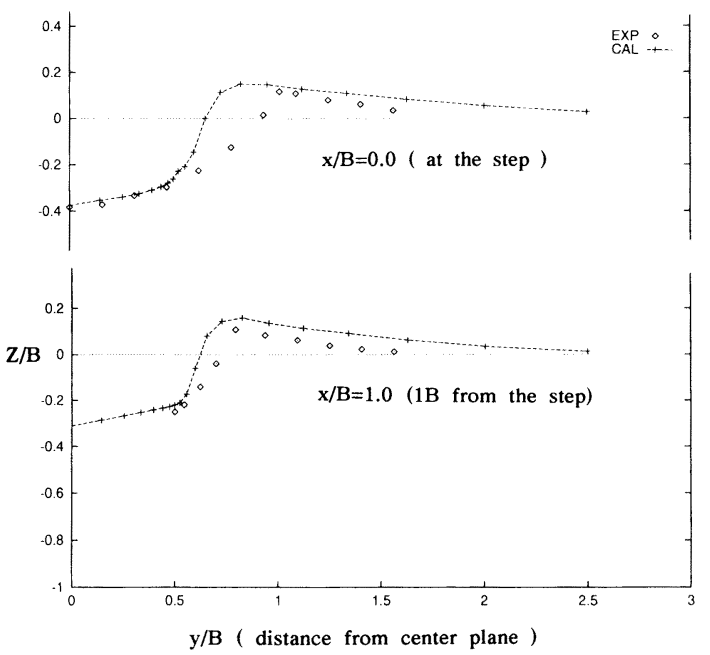

Fig. 10 Transverse wave profile for the planing craft

and overturning motion of the wave is also observed near the centerplane.

The time evolution of the wave profile on the centerplane is shown sequentially in Fig. 12. The velocity of the uniform flow is linearly accelerated until the nondimensional time is 5.0. The free-surface at the transom stern moves gradually downwards, and finally at

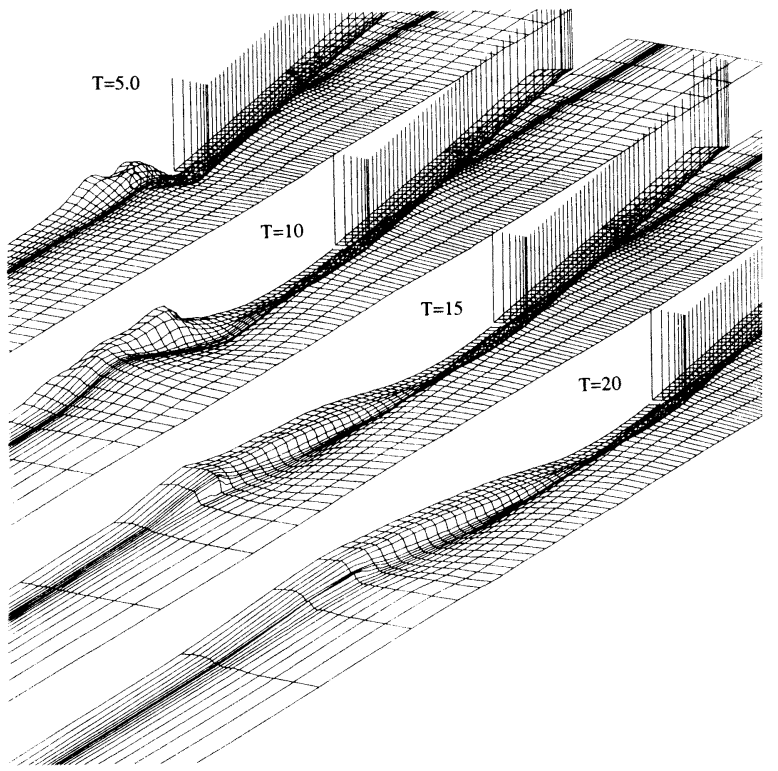

Fig. 11 Perspective view of the wave for the planing craft

nondimensional time $t=3.5$ it becomes flush with the bottom of the hull.

\section{Concluding remarks}

Quantitative as well as qualitative accuracy of the new CFD method is evaluated through the simulation of the flow around the Wigley's hull, and it is suggested that the number of the grid points in the vertical direction much influences on the accuracy. It is demonstrated in the simulation of the flow around the tanker model that nonlinearity of the wave, energy dissipation and its effect on the wake formation are numerically realized. However, the problem of quantitative accuracy is left for further validation and improvement. Another highly nonlinear flow, the flow around high speed planing boat is simulated and the versatile applicability of the present method to the transom flow is demonstrated. It can be generally said that the problems involving nonlinear hydrodynamical mechanism can be conveniently dealt with by use of the marker-density method on the free surface.

\section{References}

1) Kawamura, T.\& Miyata, H.(1994); Simulation of the Nonlinear Ship Flows by Density-Function Method, J. Soc. Nav. Arch. Japan, vol. 176, pp. 110.

2) Miyata, H. ,Zhu, M. \& Watanabe, O. (1992) : Numerical Study on a Viscous Flow with FreeSurface Waves About a Ship in Steady Straight Course by a Finite-Volume Method, J. Ship Research, vol. 36, No. 4, pp. 332 345 .

3) Zhu, M., Yoshida, O., Miyata, H. and Aoki, K. (1989) ; Verification of the Viscous Flow-Field Simulation for Practical Hull Forms by a Finite- 

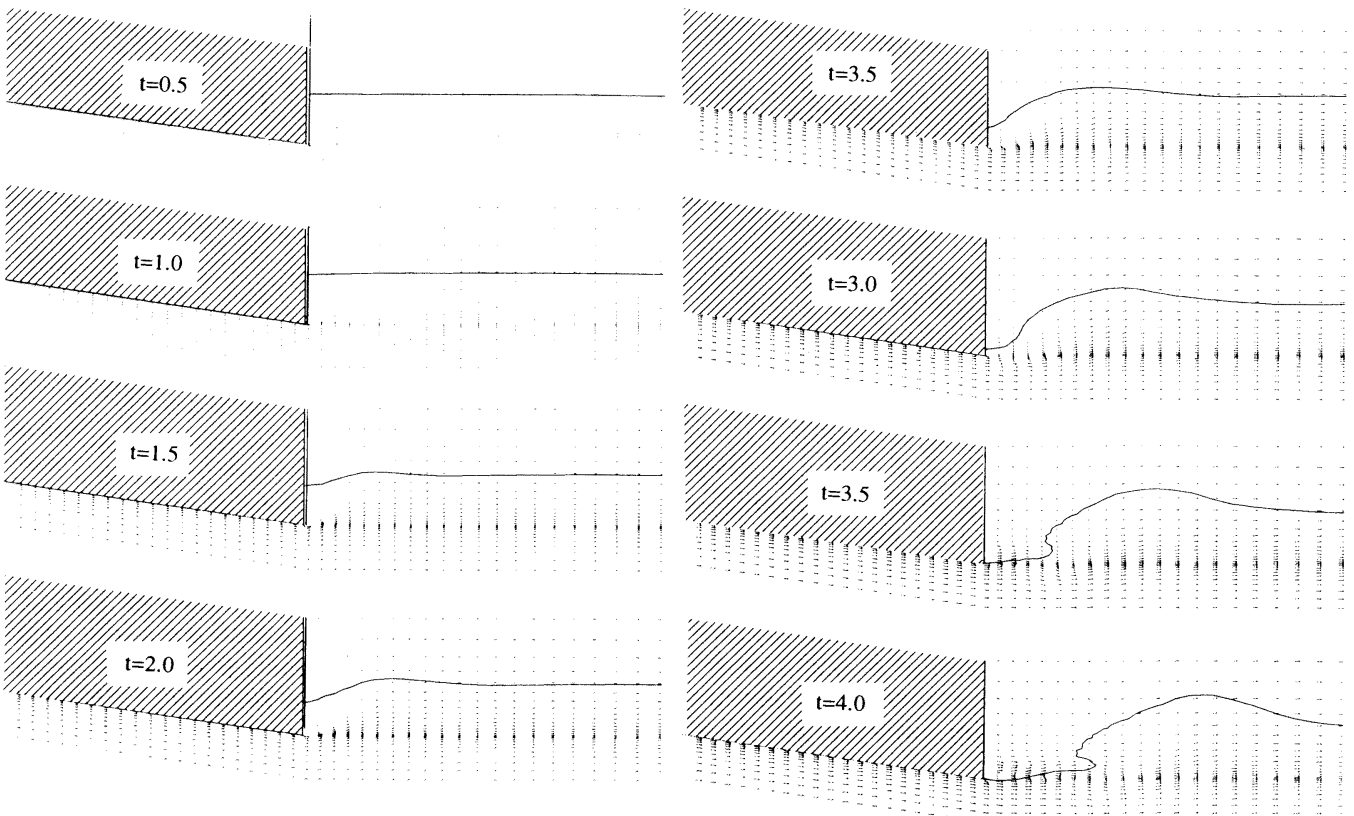

Fig. 12 Time sequence of the evolution of the wave profile on the centerplane for the planing craft

Volume Method, 6th Intern. Conf. Num. Ship. Hydro, pp. 469-488

4) Hirt, C. W. \& Nichols, B. D. (1981) ; Volume of Fluid (VOF) Method for the Dynamics of Free Boundaries, J. Comput. Phys., vol. 39, pp. 201-225.

5) Miyata, H. , Katsumata, M., Lee, Y.- G. \& Kajitani, H. (1988) ; A Finite-Difference Simulation Method for Strongly Interacting Two-Layer Flow, J. Soc. Naval Archt. Japan, vol. 163, pp. 116.

6) Park, J.-C., Zhu, M. \& Miyata, H. (1993) ; On the Accuracy of Numerical Wave Making Tech niques, J. Soc. Naval Archt. Japan, vol. 173, pp. 3544.

7) Park, J.-C. \& Miyata, H. (1994); Numerical Simulation of 2D and 3D Breaking Waves by Finite-Difference Method, J. Soc. Naval Archt. Japan, vol. 175, pp. 11-24. (Japanese)

8) Baba, E. (1969) ; A New Compenent of Viscous Resistance, J. Soc. Nav. Arch. Japan, vol. 125, pp. 23-34.

9) Miyata, H. \& Inui, T. (1984) ; Nonlinear Ship Waves, Advances in Applied Mech., vol. 24, pp. 215-288.

10) Savitsky, D (1988) ; Wake Shapes Behind Plan ing Hull Forms, Intern. High-Performance Vehi- cle Conf., Shanghai, China., VII-1.

11) Hino, T. (1989) ; Computation of a Free Surface Flow around an Advancing Ship by The NavierStokes Equations, 5th Intern. Conf. Num. Ship. Hydro., pp. 69-82.

12) Miyata, H. , Nishimura, S. \& Masuko, A. (1985); Finite Difference Simulation of Nonlinear Waves Generated by Ships of Arbitrary Three-Dimensional Configuration, J. Comput. Phys., vol. 60, No. 3, pp. 391-436.

13) Taneda, S. (1974) ; Necklace vortices, J. Phys. Soc. Japan, vol 36, pp. 298-303.

14) Welch, H. E., Harlow, F. H., Shannon, J. P., and Daly, B. J. (1966) ; The MAC Method, Los Alamos Scientific Lab. Report, LA-3425.

15) Chan, R. K-C. \& Street, R. L. (1970) ; A Computer Study of Finite Amplitude Water Waves, J. Compt. Phys., vol. 6, pp. 68-94.

16) Miyata, H. (1986) ; Finite Difference Simulation of Breaking Waves, J. Comput. Phys., vol. 65, No. 1, pp. 179-214.

17) Nichols, B. D. \& Hirt, C. W. (1971) ; Improved Free-Surface Boundary Conditions for Numerical Incompressible-Flow Claculations, J. Compt. Phys., vol. 8, pp. 434-448. 